\title{
Hiệu quả kỹ thuật trong sản xuất bắp lai ở Đồng bằng Sông Cửu Long
}

\section{Technical efficiency of hybrid maize production in the Mekong Delta}

\author{
Lê Văn Dễ ${ }^{*}$, Phạm Lê Thông ${ }^{1}$ \\ ${ }^{1}$ Trường Đại học Cần Thơ, Việt Nam \\ *Tác giả liên hệ, Email: lvde@ctu.edu.vn
}

THÔNG TIN

DOI:10.46223/HCMCOUJS. soci.vi.14.1.458.2019

Ngày nhận: 10/10/2018

Ngày nhận lại: 06/03/2019

Duyệt đăng: 06/03/2019

Tù khóa:

hàm sản xuất biên ngẫu nhiên, hiệu quả kỹ thuật sản xuất bắp lai

\section{TÓM TẮT}


Keywords:

technical efficiency of hybrid maize production, stochastic production frontier function

the ability to choose optimal inputs for each farming household. As a result, the average productivity loss from technical inefficiency was about 0.19 tons per 1,000 square meters in a crop. Key factors found to significantly affect productivity are phosphorus fertilizer, number of family laborers, and the cost of herbicide and fuel. In addition, significant determinants positively related to technical efficiency include regional characteristics, survival ratio of seeds, years of farming experience, number of growing days, number of crops per year and number of crop plots.

\section{1. Đặt vấn đề}

Bắp lai là một trong những nguồn nguyên liệu quan trọng cho các ngành công nghiệp chế biến thức ăn chăn nuôi, sản xuất thực phẩm và một số ngành công nghiệp khác. Hàng năm nước ta phải nhập khẩu bình quân hơn 5,5 triệu tấn bắp, tương đương 1,2 tỉ USD để làm nguyên liệu chế biến thức ăn chăn nuôi và theo dự báo nhu cầu còn tăng (Tổng cục Hải quan, 2016). Chính vì thế Chính Phủ đã ban hành nhiều chính sách để phát triển hoạt động sản xuất nhằm tăng sản lượng sản xuất trong nước đạt 8,5 triệu tấn/năm vào năm 2020 giảm phụ thuộc vào nhập khẩu. Do đó, cả nước sẽ chuyển đổi 236.000 ha đất trồng lúa kém hiệu quả sang canh tác bắp từ nay đến năm 2020, trong đó vùng Đồng bằng sông Cửu Long (ĐBSCL) chuyển đổi 83.000 ha theo Quyết định 3367/QĐ-BNN của Bộ NN\&PTNT, ban hành ngày 31/07 2014.

Hiện nay, diện tích sản xuất bắp ở ĐBSCL khoảng 38 - 40 nghìn ha/năm. Mặc dù, diện tích sản xuất còn thấp nhưng ĐBSCL là một trong những vùng sản xuất đạt năng suất cao, hơn gấp 1,3 lần năng suất bình quân cả nước (Tổng cục Thống kê, 2014). Sản xuất bắp lai trên nền đất lúa kém hiệu quả còn cho thu nhập cao hơn gấp 1,5 - 1,8 lần so với sản xuất lúa (Cục trồng trọt, 2014). Điều này cho thấy triển vọng để mở rộng và phát triển cây trồng này. Tuy nhiên, việc sản xuất bắp ở ĐBSCL còn gặp nhiều khó khăn và trở ngại; Thứ nhất, bởi trình độ và kinh nghiệm sản xuất bắp của phần lớn nông dân còn khá hạn chế do từ lâu đã quen với sản xuất lúa; Thư hai, việc ứng dụng cơ giới hóa vào sản xuất còn nhiều trở ngại nên chi phí sản xuất còn cao, sản phẩm không có lợi thế cạnh tranh so với sản phẩm cùng loại nhập khẩu; Thứ $b a$, hoạt động sản xuất rất manh mún, nhỏ lẻ nên gặp khó khăn trong kêu gọi doanh nghiệp liên kết tiêu thụ cho nên hầu hết nông dân phải bán sản phẩm cho thương lái với giá cả rất bấp bênh. Chính vì thế các nông hộ trong vùng còn nhiều bất cập trong vấn đề sử dụng các nguồn lực đầu vào trong sản xuất, cũng như không mạnh dạn đầu tư phát triển sản xuất theo hướng tối ưu các nguồn lực đầu vào và áp dụng các tiến bộ kỹ thuật mới vào sản xuất. Cho nên hiệu quả kỹ thuật trong sản xuất đạt được sẽ không cao. Nghiên cứu này nhằm ước lượng mức hiệu quả kỹ thuật, cũng như phân tích các yếu tố ảnh hưởng đến mức hiệu quả kỹ thuật trong sản xuất bắp lai trên địa bàn nghiên cứu. Dựa trên kết quả nghiên cứu, các giải pháp nâng cao hiệu quả kỹ thuật trong sản xuất bắp lai cho các nông hộ trên địa bàn nghiên cứu sẽ được đề xuất. 


\section{Phương pháp luận và phương pháp nghiên cứu}

\subsection{Phương pháp luận và phương pháp nghiên cúu}

Theo Farrell (1957), hiệu quả sản xuất được tạo thành bởi ba thành phần: hiệu quả kỹ thuật, hiệu quả phân phối (hay hiệu quả giá) và hiệu quả kinh tế. Hiệu quả kinh tế hay hiệu quả tổng cộng là tích của hiệu quả kỹ thuật và phân phối $\left(E E_{i}=T E_{i} \times A E_{i}\right.$, trong đó: $E E_{i}, T E_{i}$ và $A E_{i}$ lần luợt là mức hiệu quả kinh tế, kỹ thuật và phân phối của nhà sản xuất thứ i).

Hiệu quả kỹ thuật: là khả năng tạo ra một lượng đầu ra cho trước từ một lượng đầu vào nhỏ nhất hay khả năng tạo ra một lượng đầu ra tối đa từ một lượng đầu vào cho trước, ứng với một trình độ công nghệ nhất định.

Hiệu quả kỹ thuật có thể được ước lượng bằng phương pháp tham số hoặc phi tham số. Trong nghiên cứu này, phương pháp tham số được sử dụng để ước lượng hiệu quả kỹ thuật, dựa trên hàm sản xuất biên ngẫu nhiên (Stochastic production frontier) được đề xuất bởi Aigner, Lovell, và Schmidt (1977), Meeusen và van Den Broeck (1977) và được phát triển bởi Battese và Coelli (1992).

Hàm sản xuất biên ngẫu nhiên là sự kết hợp những thành phần của hiệu quả sản xuất. Bất kỳ những sai sót nào trong quá trình sản xuất đều được giả định là dẫn tới việc giảm năng suất (Ali, Parikh, \& Shah, 1994). Hàm giới hạn ngẫu nhiên có phần sai số tổng hợp gồm hai phần độc lập với nhau:

$$
Y_{i}=f\left(x_{i j}\right) \exp \left(v_{i}-u_{i}\right)
$$

Trong đó: $Y_{i}$ là năng suất của nông hộ thứ $i$, được tính bằng sản lượng sản phẩm đầu ra trên một đơn vị diện tích sản xuất; $X_{i j}$ là lượng các yếu tố đầu vào thứ $j$ của nông hộ $i$ sử dụng trong sản xuất.

$$
\varepsilon_{i}=v_{i}-u_{i}
$$

Trong đó, $v_{i}$ là phần sai số đối xứng, biểu diễn tác động của những yếu tố ngẫu nhiên, có phân phối chuẩn với giá trị kỳ vọng là 0 và phương sai $\delta_{v}^{2}\left(v \sim N\left(0, \sigma_{v}^{2}\right)\right) . u_{i}>0$ là phần sai số một đuôi có giá trị dương và có thể có phân phối xác suất với các giá trị dương, biểu diễn phần phi hiệu quả được tính từ chênh lệch giữa mức năng suất thực tế $\left(Y_{i}\right)$ và giá trị năng suất tối đa có thể có của nó $\left(Y_{i}^{\max }\right)$ được cho bởi hàm sản xuất biên ngẫu nhiên, tức là: $Y_{i}-Y_{i}^{\max }$. Nếu $u_{i}=0$, hoạt động sản xuất của hộ nằm trên đường biên (frontier), tức đạt mức năng suất tối đa dựa trên các yếu tố sản xuất có được. Nếu $u_{i}>0$, hoạt động sản xuất của hộ nằm dưới đường biên (frontier), tức $Y_{i}<Y_{i}^{\max }$ và hiệu số giữa $Y_{i}$ và $Y_{i}^{\max }$ là phần phi hiệu quả và hệ số này càng lớn, hiệu quả kỹ thuật đạt được càng thấp (Coelli và cộng sự, 2005). Do đó, hiệu quả kỹ thuật của một nông hộ trong sản xuất có thể được tính dựa trên tỷ lệ năng suất được quan sát với năng suất biên tương ứng, cụ thể như sau:

$$
I E E=\frac{f\left(X_{i j}\right) \cdot \exp \left(v_{i}-u_{i}\right)}{f\left(X_{i j}\right) \cdot \exp \left(v_{i}\right)}=\exp \left(-u_{i}\right)
$$


Khi đó, $u_{i}$ là một hàm phi hiệu quả kỹ thuật (Technical inefficiency function) được dùng để giải thích các yếu tố ảnh hưởng đến phi hiệu quả kỹ thuật. Do đó, dấu âm của hệ số ước lượng trong hàm phi hiệu quả kỹ thuật sẽ được giải thích quan hệ thuận chiều với hiệu quả kỹ thuật. Hàm phi hiệu quả có dạng như sau:

$$
u_{i}=\alpha_{0}+\sum_{j=1}^{k} \alpha_{j} W_{j i}+\xi_{i}
$$

Trong đó: $W_{j i}$ thể hiện cho các yếu tố ảnh hưởng đến phi hiệu quả kỹ thuật (các đặc điểm về nông hộ, đặc điểm về mô hình sản xuất, ...); $\xi_{i}$ là giá trị sai số thể hiện những yếu tố ngoài mô hình.

Tuy nhiên, ước lượng kém hiệu quả $u_{i}$ trong phương trình (3) thường khó được tách ra khỏi những tác động ngẫu nhiên $v_{i}$.

Theo Maddala (1977), giá trị trung bình và phương sai tổng thể của $u$ được tách khỏi $v$ được ước lượng bởi:

$$
E(u)=\delta_{u} \sqrt{\frac{2}{\pi}} \quad \operatorname{Var}(u)=\delta_{u}^{2}(\pi-2) / \pi
$$

Jondrow, Lovell, Materov, và Schmidt (1982) cũng đã trình bày cách tính hiệu quả mà loại trừ yếu tố ngẫu nhiên. Họ cho rằng $u_{i}$ của mỗi quan sát được tính bằng phân phối có điều kiện của $u_{i}$, ứng với $e_{i}$ cho truớc. Với phân phối chuẩn cho trước $v_{i}$ và nửa chuẩn của $u_{i}$, kỳ vọng của mức phi hiệu quả của từng nông trại $u_{i}$, với $e_{i}$ cho trước là: $E\left(u_{j} / e_{j}\right)=\delta\left[\frac{f(.)}{1-F(.)}-\left(\frac{\lambda e_{j}}{\delta}\right)\right]$ Trong đó: $\delta^{2}=\delta_{u}^{2} \delta_{v}^{2} / \delta^{2}, \lambda=\delta_{u} / \delta_{v}, \delta=\sqrt{\delta_{u}^{2}+\delta_{v}^{2}}, f($.$) \quad và$ $F\left(\right.$. ) lần lượt là hàm phân phối mật độ chuẩn tắc và xác suất tích luỹ tại $\left(\frac{\lambda e_{j}}{\delta}\right)$. Theo Battese và Coelli (1992) thì tỷ số phương sai $\lambda^{\prime}=\left(\delta_{u}^{2} / \delta^{2}\right)$ luôn nằm trong giới hạn từ 0 đến 1 và nó được dùng để giải thích phần sai số nào sẽ tác động và làm biến đổi năng suất hay lợi nhuận thực tế so với năng suất hay lợi nhuận tối đa. Nếu tỷ số phương sai $\lambda$ ' dần về 1 , tỉ số này sẽ cho biểt được phần kém hiệu quả phần lớn là do sự tác động của các yếu tố mà nông dân có thể kiểm soát được. Nếu $\lambda$ ' tiến dần về 0 thì phần kém hiệu quả của nông hộ chủ yếu là do sự tác động của các yếu tố ngẫu nhiên.

\subsection{Mô hình nghiên cúu thục nghiệm}

Nhằm ước lượng mức hiệu quả kỹ thuật của các nông hộ trong sản xuất trên cơ sở hàm sản xuất biên ngẫu nhiên. Hàm sản xuất biên ngẫu nhiên được thiết lập, có dạng như sau:

$$
\ln Y_{i}=\alpha_{0}+\sum_{k=1}^{4} \alpha_{k} \ln X_{k i}+\sum_{j=1}^{6} \alpha_{j} \ln C_{j i}+\alpha_{i} \ln L_{i}+e_{i}
$$


Trong đó:

$Y_{i}$ : Là năng suất (tức sản lượng sản phẩm đầu ra tính trên đơn vị diện tích (kg/công $\left.\left(1.000 \mathrm{~m}^{2}\right) / \mathrm{vụ}\right)$

$\alpha_{0}$ : Hệ số chặn của hàm sản xuất biên ngẫu nhiên

$\alpha_{k}, \alpha_{j}, \alpha_{i}$ : Hệ số tương quan thứ $i$ ứng với biến độc lập

$X_{k i}$ : Lượng các yếu tố đầu vào biến đổi (lượng nguyên chất phân đạm; lân; kali và lượng giống), đơn vị tính là $\mathrm{kg} / \mathrm{công}\left(1.000 \mathrm{~m}^{2}\right) / v u ̣$

$C_{j i}$ : Là chi phí các yếu tố đầu vào (chi phí thuốc cỏ; sâu, bệnh; dưỡng; chi phí nhiên liệu; chi phí lao động thuê; chi phí cố định), đơn vị tính là đồng/công $\left(1.000 \mathrm{~m}^{2}\right) / v u ̣$

$L_{h i}$ : Là số ngày công lao động gia đình sử dụng trên công $\left(1.000 \mathrm{~m}^{2}\right)$ trong 1 vụ sản xuất bắp lai, đơn vị tính là ngày công/công $\left(1.000 \mathrm{~m}^{2}\right) / v u ̣$

$e_{i}$ : giá trị sai số hỗn hợp của mô hình $\left(e_{i}=v_{i}-u_{i}\right)$

Bên cạnh, để phân tích các yếu tố ảnh hưởng đến hiệu quả kỹ thuật trong sản xuất, nhằm có cơ sở đề xuất một số giải pháp nâng cao hiệu quả kỹ thuật. Dựa trên mức hiệu quả kỹ thuật vừa ước lượng được từ phương trình (6) và các yếu tố đặc tính kinh tế xã hội của mỗi nông hộ khảo sát được, nghiên cứu sử dụng phân tích hồi quy tương quan nhằm tìm ra các yếu tố có ảnh hưởng đến mức hiệu quả kỹ thuật của nông hộ, mô hình phân tích hồi quy tương quan có dạng:

$$
T E_{i}=\delta_{0}+\sum_{k}^{11} \delta_{k} \mathrm{Z}_{i k}+\varepsilon_{i}
$$

Trong đó:

$T E_{i}$ : Phi hiệu quả kỹ thuật của nông hộ thứ i, được tính bằng đơn vị ( $\left.\%\right)$,

$Z_{1,2,3, \ldots .11}$ : là các yếu tố đặc tính kinh tế xã hội nông hộ, cụ thể: $Z_{1}$ : Sản xuất bắp tại Đồng Tháp $\left(1=\right.$ Đồng Tháp, $0=$ địa phương khác); $Z_{2}$ : Sản xuất bắp tại Trà Vinh $(1=$ Trà Vinh, $0=$ địa phương khác); $Z_{3}$ : Tham gia tập huấn $\left(1=\right.$ có, $0=$ không); $Z_{4}$ : Tỉ lệ sống sau gieo (\%); $Z_{5}$ : Số năm kinh nghiệm sản xuất bắp lai (năm); $Z_{6}$ : Số lao động trong hộ tham gia sản xuất bắp lai (người); $Z_{7}$ : Dịch bệnh ( $1=$ có, $0=$ không); $Z_{8}$ : Thời gian đất sử dụng trồng bắp lai (năm); $Z_{9}$ : Số vụ sản xuất trong năm (vụ/năm); $Z_{10}$ : logagit diện tích sản xuất bắp lai; $Z_{11}$ : Số mảnh đất sản xuất bắp lai (mảnh).

\subsection{Số liệu nghiên cúu}

Do đặc thù các nông hộ sản xuất bắp lai ở vùng ĐBSCL không phân tán như các loại sản phẩm nông nghiệp khác, mà có sự phân bố tập trung theo địa bàn trong từng địa phương trong vùng. Nhóm nghiên cứu chọn 3 tỉnh có diện tích sản xuất bắp lai dẫn đầu vùng ĐBSCL để khảo sát. Các tỉnh được chọn khảo sát, đại diện cho 2 vùng sinh thái khác nhau: An Giang, Đồng Tháp là 2 tỉnh đại diện cho lưu vực đầu nguồn sông Cửu Long, còn Trà Vinh đại diện cho lưu vực hạ nguồn.

Trong mỗi tỉnh, nhóm nghiên cứu chọn ra huyện có diện tích sản xuất lớn và tập trung của tỉnh, trên cơ sở đó mỗi huyện chọn ngẫu nhiên từ 2-3 xã để thực hiện khảo sát. Hộ khảo sát được chọn ngẫu nhiên từ danh sách các hộ trồng bắp lai trên địa bàn xã do Ủy ban nhân dân 
các xã cung cấp. Kết quả khảo sát được 240 nông hộ, trong đó tỉnh An Giang (cụ thể là huyện An Phú) có 117 hộ, tỉnh Đồng Tháp (huyện Thanh Bình) 66 hộ và tỉnh Trà Vinh (huyện Trà Cú) 57 hộ. Bên cạnh đó, do mỗi vùng có điều kiện tự nhiên và tập quán sản xuất khác nhau nên số vụ sản xuất trên các địa bàn khảo sát trong vùng cũng khác nhau: An Giang sản xuất từ 2-3 vụ/năm (trung bình là 2,5 vụ/năm), Đồng Tháp sản xuất từ 1-2 vụ/năm (trung bình là 2,1 vụ/năm) và Trà Vinh là 1 vụ/năm. Để đảm bảo sự thống nhất giữa các địa bàn trong vùng, trong nghiên cứu này chọn vụ gieo trồng trong khoảng thời gian từ tháng 10/2017 đến tháng 1/2018 (vụ Đông Xuân) để thực hiện phân tích vì đây là vụ mà cả 3 tỉnh đều có sản xuất.

\section{Kết quả và thảo luận}

\section{1. Đặc điểm chung về nông hộ và kết quả tù̀ hoạt động sản xuất bắp lai}

Kết quả khảo sát 240 nông hộ trên địa bàn nghiên cứu cho thấy một số đặc điểm chung của các nông hộ sản xuất bắp lai ở ĐBSCL, được thể hiện ở Bảng 1 .

\section{Bảng 1}

Đặc điểm chung về nông hộ trồng bắp ở ĐBSCL

\begin{tabular}{lcc}
\hline \multicolumn{1}{c}{ Đặc điểm } & Đơn vị tính & Giá trị trung bình \\
\hline Diện tích sản xuất & công $\left(1.000 \mathrm{~m}^{2}\right) /$ hộ & 6,20 \\
Số năm kinh nghiệm & năm & 13,79 \\
Trình độ học vấn chủ hộ & số năm đi học & 5,08 \\
Số lượng lao động trong hộ & lao động/hộ & 2,68 \\
Số lượng lao động tham gia sản xuất bắp & lao động/hộ & 2,23 \\
- Lao động Nam & lao động/hộ & 1,23 \\
- Lao động nṹ & lao động/hộ & 1,06 \\
Số vụ sản xuất & vụ/năm & 2,30 \\
Tỉ lẹ̣ tham gia tập huấn & $\%$ & 55,04 \\
Tî lệ tham gia liên kết (đầu vào, đầu ra) & $\%$ & 20,77 \\
\hline
\end{tabular}

Nguồn: Kết quả tổng hợp từ số liệu khảo sát, năm 2018

Diện tích sản xuất bắp lai bình quân của mỗi nông hộ trên địa bàn nghiên cứu là 6,2 công $\left(1.000 \mathrm{~m}^{2}\right)$, trong đó An Giang là địa phương có diện tích sản xuất bắp lai bình quân trên mỗi nông hộ cao nhất với 7,03 công/hộ, Đồng Tháp là 5,62 công/hộ và Trà Vinh là 5,24 công/hộ. Số năm kinh nghiệm trung bình trong sản xuất bắp lai của nông hộ trên địa bàn nghiên cứu là gần 14 năm, An Giang và Đồng Tháp là những địa phương tham gia hoạt động sản xuất bắp lai khá lâu, với số năm kinh nghiệm bình quân ở 2 địa phương này lần lượt là 17 và 15 năm, trong khi đó ở Trà Vinh có số năm kinh nghiệm bình quân chỉ khoảng 6 năm. Hầu hết các nông hộ tham gia sản xuất bắp có trình độ học vấn còn hạn chế, bình quân có học vấn cấp 1 , nên đây có thể là một trong những rào cản đối với nông hộ trong việc tiếp thu các tiến bộ khoa học kỹ thuật vào sản xuất cũng như ảnh hưởng đến vấn đề ra quyết định sử dụng có hiệu quả các nguồn lực trong sản xuất. Số lao động bình quân tham gia hoạt động sản xuất bắp lai là 2,68 người/hộ, chiếm gần $91 \%$ tổng số lao động trong hộ điều này cho thấy hoạt động sản xuất bắp lai là một trong những hoạt động kinh tế quan trọng của các nông hộ được khảo sát trên địa bàn nghiên cứu. Số vụ sản xuất bình quân là 2,3 vụ/năm, trong đó An Giang là địa phương có số vụ sản 
xuất bình quân trong năm cao nhất với khoảng 2,5 vụ/năm, Đồng Tháp là 2,1 vụ/năm và Trà Vinh là 1 vụ/năm, trong đó vụ Đông Xuân là mùa vụ được tất cả các địa phương chọn sản xuất. Mặc dù sản xuất bắp lai là hoạt động sản xuất khá quan trọng trong hoạt động kinh tế của các nông hộ nhưng tỉ lệ nông hộ tham gia tập huấn còn hạn chế, chỉ chiếm khoảng 55\%. Đặc biệt, số nông hộ có tham gia hoạt động liên kết (cung ứng đầu vào và tiêu thụ sản phẩm) còn rất thấp, hiện chỉ đạt xấp xỉ $21 \%$, đây là một những những vấn đề khó khăn và tồn tại ảnh hưởng khá lớn đến hoạt động sản xuất.

\section{Bảng 2}

Doanh thu, chi phí và lợi nhuận của hoạt động sản xuất bắp lai

\begin{tabular}{lccc}
\hline Các chỉ tiêu & Đơn vị tính & $\begin{array}{c}\text { Trung } \\
\text { bình }\end{array}$ & $\begin{array}{c}\text { Độ lệch } \\
\text { chuẩn }\end{array}$ \\
\hline Doanh thu & triệu đồng/công $\left(1.000 \mathrm{~m}^{2}\right) / \mathrm{vụ}$ & 4,34 & 1,05 \\
- Năng suất & tấn/công $\left(1.000 \mathrm{~m}^{2}\right) / v u ̣$ & 1,10 & 0,35 \\
- Giá bán & nghìn đồng//kg & 3,96 & 0,41 \\
Chi phí & triệu đồng/ công/vụ & 2,28 & 0,58 \\
- Chi phí giống & triệu đồng/ công/vụ & 0,30 & 0,13 \\
- Chi phí phân bón & triệu đồng/ công/vụ & 0,89 & 0,46 \\
- Chi phí thuốc nông dược & triệu đồng/ công/vụ & 0,23 & 0,21 \\
- Chi phí nhiên liệu & triệu đồng/ công/vụ & 0,12 & 0,11 \\
- Chi phí lao động thuê & triệu đồng/ công/vụ & 0,30 & 0,11 \\
- Chi phí cố định & triệu đồng/ công/vụ & 0,44 & 0,20 \\
Lợi nhuận & triệu đồng/ công/vụ & 2,06 & 1,23 \\
\hline
\end{tabular}

Nguồn: Kết quả tổng hợp từ số liệu khảo sát, năm 2018

Với mức năng suất bình quân đạt xấp xỉ 1,10 tấn/công $\left(1.000 \mathrm{~m}^{2}\right) / v u ̣$ và giá bán sản phẩm đầu ra (với hình thức bắp tươi sau khi được tuốt hạt) bình quân là 3,96 ngàn đồng $/ \mathrm{kg}$. Doanh thu trung bình mà các nông hộ sản xuất bắp lai trên địa bàn nghiên cứu đạt được là 4,34 triệu đồng/công $\left(1.000 \mathrm{~m}^{2}\right) / v u ̣$. Tổng mức chi phí sản xuất bình quân là 2,28 triệu đồng/công/vụ, trong đó chi phí phân bón là khoản mục chi phí chiếm tỉ trọng lớn nhất, chiếm đến 39,06\% trong tổng chi phí $(0,89$ triệu đồng/công/vụ); kế đến là chi phí lao động thuê mướn chiếm 19,33\% (0,44 triệu đồng/công/vụ); chi phí cố định chiếm 13,05\% (0,30 triệu đồng/công/vụ); chi phí giống chiếm $13,01 \%$ (gần 0,3 triệu đồng/công/vụ), chi phí thuốc nông dược chiếm $10,29 \%$ ( 0,23 triệu đồng/công/vụ) và chi phí nhiên liệu chiếm $5,26 \%$ ( 0,12 triệu đồng/công/vụ).

Mức lợi nhuận bình quân mà các nông hộ trên địa bàn nghiên cứu đạt được là 2,06 triệu đồng/công/vụ. Tuy nhiên thực tế mức lợi nhuận đạt được có sự biến động khá lớn giữa các nông hộ, thể hiện qua giá trị độ lệch chuẩn khá lớn (1,23 triệu đồng) thể hiện ở Bảng 2 . Đặc biệt, có khoảng 4,17\% nông hộ (10 nông hộ trong 240 nông hộ khảo sát) trên địa bàn nghiên cứu bị lỗ (lợi nhuận âm), với mức lỗ bình quân khoảng 0,28 triệu đồng/công/vụ và chủ yếu là nông hộ thuộc địa bàn tỉnh Trà Vinh. Trung bình trên mỗi công đất $\left(1.000 \mathrm{~m}^{2}\right)$ sản xuất bắp lai trong một vụ sản xuất, nông hộ phải đầu tư bình quân khoảng 5,39 ngày công lao động gia đình. Cho 
nên, nếu tính theo mức giá bình quân lao động thuê mướn phục vụ sản xuất bắp lai tại địa bàn vào thời điểm khảo sát là 180.000 đồng/ngày, thì chi phí cơ hội lao động gia đình trung bình là 0,97 triệu đồng/công/vụ. Do đó tính cả chi phí lao động gia đình thì tổng chi phí sản xuất là 3,25 triệu đồng/công/vụ và lợi nhuận đạt được chỉ còn 1,09 triệu đồng/công/vụ.

\subsection{Kết quả uơóc lự̂ng hàm sản xuất biên ngẫu nhiên}

Kết quả ước lượng từ mô hình (6) bằng phương pháp ước lượng MLE (Maximum likelihood estimation) được trình bày ở Bảng 3 . Mô hình có ý nghĩa thống ở mức $1 \%\left(\operatorname{Pr}>^{2}=\right.$ 0,000), chứng tỏ các biến độc lập được chọn trong mô hình có ảnh hưởng đến biến phụ thuộc.

\subsubsection{Mối quan hệ giũa luợng, chi phí của các yếu tố đầu vào và năng suất}

Phân bón là một trong những nguồn lực đầu vào quan trọng trong các hoạt động sản xuất nông nghiệp, đặc biệt trong sản xuất bắp lai. Trên địa bàn nghiên cứu chi phí này chiếm đến 39,06\% trong tổng chi phí sản xuất. Qua kết quả ước lượng trong Bảng 3 cho thấy, trong nhóm các yếu tố phân bón thì chỉ riêng có yếu tố lượng phân lân có hệ số ước lượng có ý nghĩa về mặt thống kê ở mức ý nghĩa $10 \%$ và có tương quan âm với năng suất, các hệ số ước lượng của những yếu tố phân đạm và kali không có ý nghĩa về mặt thống kê ở mức $10 \%$. Từ kết quả ước lượng này đã thể hiện phần nào vấn đề bất hợp lý trong việc sử dụng phân bón của nông hộ. Đặc điểm này tương đồng với hành vi của nông hộ ở địa bàn nghiên cứu trong việc sử dụng phân bón trong sản xuất lúa (Nguyen, 2012; Pham, Huynh, \& Tran, 2011).

Hệ số ước lượng của biến lượg giống không có ý nghĩa về mặt thống kê ở mức ý nghĩa $10 \%$, đồng nghĩa với lượng giống trong trường hợp này không ảnh hưởng đến năng suất. Nguyên nhân có thể được giải thích do hầu hết các nông hộ trồng bắp lai không sử dụng giống tự sản xuất, mà thay vào đó hầu hết sử dụng giống do các công ty chuyên sản xuất giống cung cấp, có khuyến cáo liều lượng sử dụng và phần lớn nông hộ sử dụng theo mức khuyến cáo này. Tương tự, trong nhóm các biến chi phí thuốc nông dược, các hệ số ước lượng của các biến; chi phí thuốc sâu-bệnh; thuốc cỏ; chi phí nhiên liệu; chi phí lao động thuê và chi phí cố định đều không có ý nghĩa thống kê, điều này đồng nghĩa với sự thay đổi của các loại chi phí này không tác động lớn đến năng suất. Tuy nhiên, riêng đối với chi phí thuốc dương hệ số ước lượng có ý nghĩa về mặt thống kê ở mức ý nghĩa $1 \%$ và âm, điều này cho thấy yếu tố này có ảnh hưởng lớn đến năng suất, cụ thể trong điều kiện các yếu tố khác không đổi khi chi phí thuốc dưỡng tăng lên $1 \%$ thì năng suất giảm $0,01 \%$.

Theo lý thuyết về sản xuất, lao động là một trong những yếu tố đầu vào quan trọng trong sản xuất, đặc biệt lao động gia đình càng có vai trò quan trọng hơn, bởi lao động gia đình thể hiện trách nhiệm đối với chính hoạt động sản xuất của nông hộ cao hơn từ đó có thể giúp mang lại hiệu quả trong sản xuất cao hơn. Tuy nhiên kết quả ước lượng thể hiện ở Bảng 3 cho thấy, số luợng ngày công lao động gia đình là biến có hệ số ước lượng có ý nghĩa thống kê ở mức $1 \%$ và âm. Điều này có nghĩa là khi số luoọng ngày công lao động gia đình tăng lên $1 \%$ trong điều kiện các yếu tố khác không đổi, thì năng suất đạt được của nông hộ sẽ giảm gần $0,08 \%$. Từ kết quả này, phần nào phản ánh chất lượng của nguồn lực lao động gia đình chưa tốt, kỹ thuật sản xuất chủ yếu dựa vào kinh nghiệm, bên cạnh phần lớn chủ hộ có độ tuổi cao và trình độ học vấn còn hạn chế, cũng như vấn đề sử dụng các nguồn lực đầu vào trong sản xuất còn nhiều bất cập. 


\section{Bảng 3}

Kết quả ước lượng hàm sản xuất biên ngẫu nhiên

\begin{tabular}{|c|c|c|c|c|c|c|}
\hline & \multicolumn{3}{|c|}{ OLS } & \multicolumn{3}{|c|}{ MLE } \\
\hline & \multicolumn{2}{|c|}{$\begin{array}{c}\text { Hệ số } \\
\text { ước lượng }\end{array}$} & $\begin{array}{c}\text { Giá trị } \\
\mathbf{t}\end{array}$ & \multicolumn{2}{|c|}{$\begin{array}{c}\text { Hệ số } \\
\text { ước lượng }\end{array}$} & $\begin{array}{c}\text { Giá trị } \\
\mathbf{Z} \\
\end{array}$ \\
\hline Hằng số & 7,764 & & 10,68 & 8,064 & & 11,53 \\
\hline logarit lượng đạm nguyên chất & 0,042 & ns & 1,32 & 0,026 & ns & 0,85 \\
\hline logarit lượng lân nguyên chất & $-0,047$ & ** & $-2,05$ & $-0,042$ & $*$ & $-1,88$ \\
\hline logarit lượng kali nguyên chất & 0,022 & ns & 1,00 & 0,024 & ns & 1,13 \\
\hline logarit lượng giống & $-0,060$ & ns & $-0,60$ & $-0,035$ & ns & $-0,36$ \\
\hline logarit chi phí thuốc cỏ & 0,001 & ns & $-0,04$ & $-0,001$ & ns & $-0,21$ \\
\hline logarit chi phí thuốc sâu, bệnh & 0,004 & ns & 0,97 & 0,004 & ns & 1,11 \\
\hline logarit chi phí thuốc dưỡng & $-0,012$ & *** & $-3,17$ & $-0,011$ & $* * *$ & $-3,20$ \\
\hline logarit chi phí nhiên liệu & 0,031 & *** & 5,49 & 0,030 & ns & 5,56 \\
\hline logarit chi phí lao động thuê & $-0,029$ & $\mathrm{~ns}$ & $-0,98$ & $-0,028$ & ns & $-1,03$ \\
\hline logarit chi phí cố định & $-0,048$ & ns & $-1,07$ & $-0,057$ & ns & $-1,33$ \\
\hline logarit lượng lao động gia đình & $-0,081$ & $* * *$ & $-2,94$ & $-0,081$ & $* * *$ & $-3,10$ \\
\hline Số quan sát & & 239 & & & 239 & \\
\hline $\mathrm{R}^{2}$ & & 0,300 & & & & \\
\hline Prob $>$ F & & 0,000 & & & & \\
\hline$\delta^{2}$ & & & & & 0,086 & \\
\hline$\delta_{v}$ & & & & & 0,189 & \\
\hline$\delta_{u}$ & & & & & 0,224 & \\
\hline$\lambda$ & & & & & 1,187 & \\
\hline
\end{tabular}

Chú thích: ${ }^{* * *},{ }^{* *},{ }^{*}$, và ${ }^{\text {ns }}$ biểu diễn các mức ý nghĩa $1 \%, 5 \%, 10 \%$ và không ý nghĩa

Nguồn: Kết quả ước lượng từ số liệu khảo sát, năm 2018.

Kết quả ước lượng thể hiện ở Bảng 3 cũng cho thấy, giá trị ' $\left(u^{2} /{ }^{2}\right) 0,58$ có nghĩa là việc kém hiệu quả kỹ thuật của nông hộ phần lớn $(58 \%)$ do các yếu tố chủ quan mà nông hộ có thể kiểm soát gây ra, tuy nhiên cũng có đến $42 \%$ được tạo nên từ các nguyên nhân khách quan (ngoài tầm kiểm soát của nông hộ).

\subsubsection{Các yếu tố ảnh hưởng đến hiệu quả kỹ thuật}

Trên cơ sở mức hiệu quả kỹ thuật vừa được ước lượng từ phương trình (6). Nghiên cứu thực hiện phân tích hồi qui tương quan, với phương pháp ước lượng OLS, kết quả ước lượng cho chỉ số $\mathrm{R}^{2}=0,24$ điều này cho biết các biến độc lập trong mô hình giải thích được $24 \%$ biến động của hiệu quả kỹ thuật. 


\section{Bảng 4}

Kết quả ước lượng các yếu tố ảnh hưởng đến phi hiệu quả kỹ thuật

\begin{tabular}{|c|c|c|c|}
\hline Các yếu tố & \multicolumn{2}{|c|}{$\begin{array}{c}\text { Hệ số } \\
\text { ước lương }\end{array}$} & $\begin{array}{c}\text { Giá trị } \\
\text { kiểm định t }\end{array}$ \\
\hline - Hằng số & 67,666 & & 7,81 \\
\hline $\begin{array}{l}\text { - Sản xuất tại Đồng Tháp (1=Đồng Tháp, } 0=\text { =ịa } \\
\text { phương khác) }\end{array}$ & 0,145 & ns & 0,17 \\
\hline $\begin{array}{l}\text { - Sản xuất tại Trà Vinh ( } 1=\text { Trà Vinh, } 0=\text { =ịa phương } \\
\text { khác) }\end{array}$ & $-4,470$ & $* *$ & $-2,47$ \\
\hline - Tập huấn (1=Có, 0=Không) & 0,877 & ns & 1,26 \\
\hline - Tỉ lệ sống sau gieo (\%) & 0,149 & $*$ & 1,66 \\
\hline - Số năm kinh nghiệm sản xuất bắp lai (năm) & 0,097 & $*$ & 1,72 \\
\hline $\begin{array}{l}\text { - Số lượng lao động trong hộ tham gia sản xuất bắp } \\
\text { lai (người) }\end{array}$ & 0,552 & ns & 1,18 \\
\hline - Dịch bệnh (1= Có, $0=$ Không) & $-1,711$ & ns & $-1,64$ \\
\hline - Thời gian đất sử dụng trồng bắp lai (năm) & $-0,078$ & * & $-1,66$ \\
\hline - Số vụ trồng trong năm (vụ/năm) & 1,372 & * & 1,67 \\
\hline - logarit diện tích sản xuất bắp lai & 0,648 & ns & 1,21 \\
\hline - Số mãnh đất sản xuất bắp lai (mãnh đất) & $-0,726$ & $*$ & $-1,77$ \\
\hline Số quan sát & & & \\
\hline Prob $>\mathrm{F}$ & & & \\
\hline $\mathrm{R}^{2}$ & & & \\
\hline
\end{tabular}

Chú thích: ${ }^{* * *},{ }^{* *},{ }^{*}$, và ${ }^{\text {ns }}$ biểu diễn các mức ý nghĩa $1 \%, 5 \%, 10 \%$ và không ý nghĩa.

Nguồn: Kết quả ước lượng từ số liệu khảo sát, năm 2018.

Do điều kiện tự nhiên ở mỗi địa phương trong vùng ĐBSCL là khác nhau, cũng như trình độ kỹ thuật và kinh nghiệm sản xuất giữa các nông hộ cũng có sự chệnh lệch. Do đó, hiệu quả kỹ thuật đạt được theo từng địa bàn trong vùng cũng có sự khác biệt. Kết quả ước lượng trong Bảng 4 cho thấy, các hệ số ước lượng của biến địa bàn sản xuất ở Trà Vinh về mặt thống kê có ý nghĩa ở mức 5\% đồng thời có tác động tương quan âm đến mức hiệu quả kỹ thuật nông hộ đạt được, trong khi đó biến địa bàn sản xuất ở Đồng Tháp hệ số ước lượng không có ý nghĩa về mặt thống kê xét ở mức ý nghĩa $10 \%$. Điều này cho thấy hiệu quả kỹ thuật trong sản xuất bắp lai của nông hộ ở Đồng Tháp và An Giang không có sự khác biệt nhau. Tuy nhiên, hiệu quả kỹ thuật trong sản xuất bắp lai của nông hộ ở Trà Vinh đạt thấp hơn so với nông hộ ở An Giang là 4,47\%, bởi điều kiện đất đai ở Trà Vinh kém màu mở hơn và nông hộ sản xuất bắp lai ở Trà Vinh hầu hết là dân tộc Khmer với trình độ kỹ thuật sản xuất còn khá hạn chế.

Hệ số của biến tỉ lệ sống sau gieo có ý nghĩa thống kê ở mức ý nghĩa $10 \%$ và tương quan dương với mức hiệu quả kỹ thuật nông hộ đạt được, có nghĩa là khi tỉ lệ cây sống sau gieo tăng lên $1 \%$ thì góp phần nâng mức hiệu quả kỹ thuật mà nông hộ đạt được lên gần $0,15 \%$. Bởi do đây là yếu tố quan trọng ảnh hưởng trực tiếp đến sản lượng cho nên ảnh hưởng đến hiệu quả kỹ thuật trong sản xuất. 
Yếu tố kinh nghiệm sản xuất sẽ mang lại một số thuận lợi nhất định cho hoạt động sản xuất của nông hộ, bởi có nhiều kinh nghiệm nông hộ sẽ đúc kết được nhiều từ thực tiễn từ đó có phương thức sản xuất hiệu quả hơn. Tuy nhiên trong một số trường hợp cũng có thể mang đến những bất lợi nhất định, bởi có nhiều kinh nghiệm trong sản xuất đôi khi các nông hộ thường chủ quan và dựa vào kinh nghiệm, ít chịu tiếp thu các tiến bộ khoa học kỹ thuật mới vào sản xuất. Theo kết quả ước lượng trong nghiên cứu này, yếu tố kinh nghiệm sản xuất của nông hộ là yếu tố có tác động tích cực đến hiệu quả kỹ thuật mà nông hộ đạt được, cụ thể với mức ý nghĩa $10 \%$ trong điều kiện các yếu tố khác không đổi, khi số năm kinh nghiệm sản xuất của nông hộ tăng lên 1 năm sẽ giúp cải thiện hiệu quả kỹ thuật của nông hộ lên gần $0,1 \%$. Nhìn chung hoạt động sản xuất bắp lai ở ĐBSCL so với các vùng miền khác trong cả nước thì vẫn còn khá non trẻ. Chính vì thế bước đầu việc tích lũy được kinh nghiệm trong điều kiện trình độ học vấn còn hạn chế đã góp phần cải thiện được hiệu quả kỹ thuật trong sản xuất.

Thông thường trong hoạt động sản xuất nông nghiệp, nếu duy trì sản xuất một đối tượng trên một mãnh đất trong nhiều năm hoặc tăng số vụ gieo trồng trên cùng một mãnh đất là hoạt động không được giới khoa học trong nông nghiệp ủng hộ. Bởi sẽ làm giảm nguồn dinh dưỡng trong đất và đây cũng sẽ là nguyên nhân tăng rủi ro dịch bệnh làm giảm năng suất và tăng chi phí sản xuất. Theo kết quả ước lượng từ khảo sát thể hiện ở Bảng 4 cho thấy, yếu tố thời gian đất sư dụng trồng bắp có hệ số ước lượng có ý nghĩa thống kê ở mức $10 \%$ và có tương quan âm với mức hiệu quả kỹ thuật đạt được, kết quả này phù hợp với nhận định vừa nêu ở trên, nghĩa là khi thời gian đất sử dụng cho canh tác bắp lai tăng thêm 1 năm thì hiệu quả kỹ thuật sẽ giảm xuống gần $0,08 \%$.

Tuy nhiên, theo kết quả ước lượng trong nghiên cứu này cho thấy, yếu tố số vu sản xuất bắp lai trong năm có quan hệ tương quan dương với mức hiệu quả kỹ thuật nông hộ đạt được, biến số này có hệ số ước lượng có ý nghĩa thống kê ở mức $10 \%$, tức là khi số vụ tăng lên 1 vụ thì hiệu quả kỹ thuật sẽ tăng lên 1,37\%. Nguyên nhân có thể được giải thích, do hoạt động sản xuất bắp lai có tính đặc thù riêng, trong thực tế hoạt động sản xuất bắp lai gần như chỉ thực hiện công việc chuẩn bị đất và làm đất duy nhất 1 lần trong năm dù sản xuất 1 hay nhiều vụ. Do vậy nếu sản xuất nhiều vụ nông hộ sẽ sử dụng nguồn lực có hiệu quả hơn, tức tiết kiệm chi phí chuẩn bị đất và làm đất hơn so với những nông hộ chỉ sản xuất 1 vụ/năm. Tuy nhiên điều này không đồng nghĩa với việc càng thâm canh tăng nhiều vụ trong năm thì hiệu quả sẽ tăng mãi, mà cần định kỳ vài năm hoặc vụ chuyển sang canh tác các đối tượng khác. Do đó, để có khuyến cáo sát thực và hiệu quả hơn cần phải có thêm các nghiên cứu chuyên môn sâu hơn của cơ quan chuyên môn về vấn đề này.

Số mãnh đất sản xuất thể hiện cho đặc điểm về điều kiện sản xuất của nông hộ, hoạt động sản xuất diễn ra không thống nhất trên cùng mãnh đất đây được xem là một trở ngại cho hoạt động tổ chức và quản lý sản xuất của nông hộ. Bởi khi sản xuất trên nhiều mãnh đất khác nhau sẽ có điều kiện tự nhiên và hạ tầng phục vụ sản xuất khác nhau nên hoạt động vận chuyển sẽ phức tạp hơn, nông hộ sẽ tiêu tốn nhiều nguồn lực hơn. Chính vì thế, theo kết quả ước lượng trong nghiên cứu, yếu tố số mãnh đất sản xuất có hệ số ước lượng có ý nghĩa về mặt thống kê ở mức $10 \%$ và có tương quan âm với mức hiệu quả kỹ thuật mà nông hộ đạt được, tức là khi số mãnh đất sản xuất bắp của nông hộ tăng lên 1 mãnh thì hiệu quả kỹ thuật sẽ giảm xuống gần $0,73 \%$ trong điều kiện các yếu tố khác không đổi. 


\subsection{Mức phân bố hiệu quả kỹ thuật của nông hộ theo địa bàn nghiên cúu}

Kết quả ước lượng và tính toán được mức hiệu quả kỹ thuật của các nông hộ đạt được, thể hiện trong Bảng 5 .

\section{Bảng 5}

Phân bố mức hiệu quả kỹ thuật

\begin{tabular}{|c|c|c|}
\hline Mức hiệu quả (\%) & Số hộ & Tỉ trọng (\%) \\
\hline $90-100$ & 25 & 10,46 \\
\hline $80-90$ & 175 & 73,22 \\
\hline $70-80$ & 31 & 12,97 \\
\hline $60-70$ & 04 & 1,67 \\
\hline $50-60$ & 03 & 1,26 \\
\hline$<50$ & 01 & 0,42 \\
\hline Trung bình & \multicolumn{2}{|c|}{84,63} \\
\hline Thấp nhất & \multicolumn{2}{|c|}{48,73} \\
\hline Cao nhất & \multicolumn{2}{|c|}{97,44} \\
\hline
\end{tabular}

Nguồn: Kết quả ước lượng từ số liệu khảo sát, năm 2018

Mức hiệu quả kỹ thuật trung bình trong sản xuất mà các nông hộ đạt là 84,63\%. Số nông hộ đạt mức hiệu quả kỹ thuật cao trong khoảng 90 đến $100 \%$ chiếm 10,46\% trong tổng số nông hộ khảo sát. Phần lớn các nông hộ đạt được mức hiệu quả trên $70 \%$, đặc biệt tập trung nhiều ở hai nhóm mức hiệu quả từ $80-90 \%$.

Sự chênh lệch về mức hiệu quả giữa hộ đạt thấp nhất $(48,73 \%)$ và cao nhất $(97,44 \%)$ là khá lớn, điều này cho thấy hoạt động sản xuất bắt lai cũng đang tiềm ẩn rất nhiều rủi ro. Vấn đề bắt nguồn từ trình độ kỹ thuật sản xuất và việc quyết sử dụng hiệu quả nguồn lực đầu vào còn có sự khác biệt khá lớn.

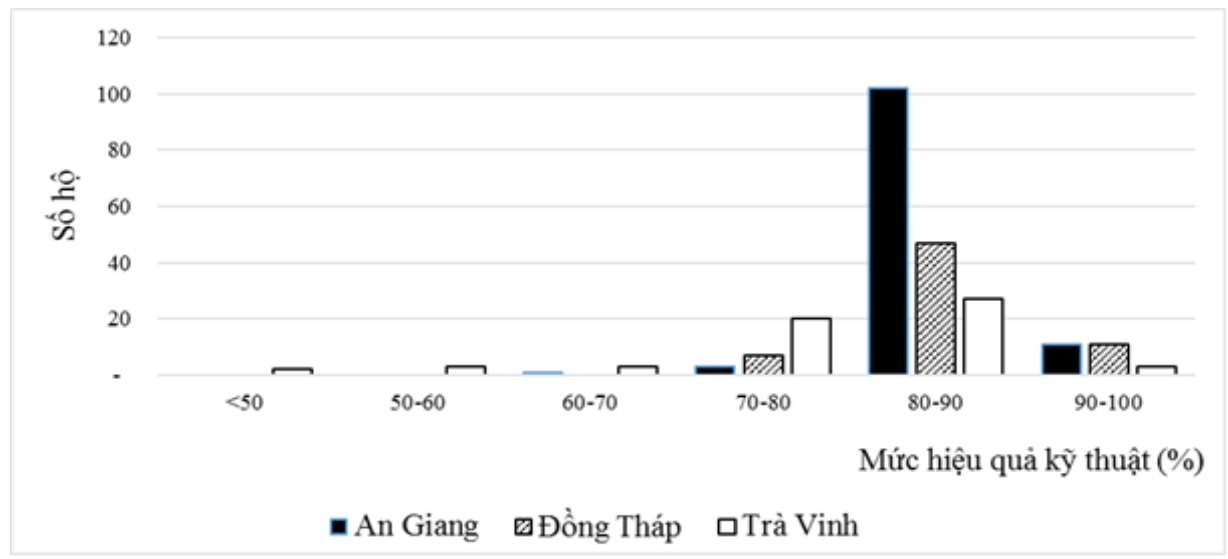

Hình 1. Phân bố mức hiệu quả kỹ thuật theo từng địa phương

Nguồn: Kết quả ước lượng từ số liệu khảo sát, năm 2018

Sự phân bố về hiệu quả kỹ thuật của nông hộ theo từng địa phương trong vùng đạt được cũng có sự khác biệt và đáng chú ý, được thể hiện ở Hình 1. 
Trong các địa phương, thì Trà Vinh là địa phương có số lượng nông hộ đạt được hiệu quả kỹ thuật phân bố ở các mức khá đa dạng, thể hiện qua phổ phân bố hiệu quả khá rộng (phân bố ở tất cả các nhóm mức hiệu quả). Trong khi đó, An Giang và Đồng Tháp là hai địa phương có số lượng nông hộ đạt các mức hiệu quả kỹ thuật có sự phân bố tập trung và tập trung chủ yếu ở nhóm mức hiệu quả từ $70 \%$ trở lên.

Từ mức hiệu quả kỹ thuật ước lượng được và mức năng suất thực tế đạt của mỗi nông hộ, có thể ước tính được phần năng suất bị thất thoát, gây ra từ việc hiệu quả kỹ thuật chưa đạt hiệu quả tối ưu (do còn tồn tại sự kém hiệu quả kỹ thuật), thể hiện ở Bảng 6. Việc kém hiệu quả này nguyên nhân do cả các yếu tố chủ quan (sử dụng các nguồn lực đầu vào chưa tối ưu) và cả các yếu tố khách quan (dịch bệnh, thời tiết, giá cả thị trường biến động, ...).

\section{Bảng 6}

Mức năng suất thất thoát phân bố theo từng nhóm mức hiệu quả

\begin{tabular}{cccc}
\hline Hiệu quả $(\%)$ & $\begin{array}{c}\text { Năng suất thực tế } \\
(\mathrm{Kg} / \text { công/vụ })\end{array}$ & $\begin{array}{c}\text { Năng suất có thể đạt } \\
(\mathrm{Kg} / \text { công/vụ })\end{array}$ & $\begin{array}{c}\text { Năng suất mất đi } \\
(\mathrm{Kg} / \mathrm{công} / \mathrm{vu})\end{array}$ \\
\hline$>90$ & 1.335 & 1.464 & 129 \\
$80-90$ & 1.115 & 1.293 & 178 \\
$70-80$ & 811 & 1.057 & 246 \\
$60-70$ & 513 & 823 & 258 \\
$50-60$ & 435 & 752 & 377 \\
$<50$ & 300 & 616 & 316 \\
\hline Trung bình & 1.100 & 1.266 & 186 \\
\hline
\end{tabular}

Nguồn: Kết quả ước lượng từ số liệu khảo sát, năm 2018

Những nông hộ đạt mức hiệu quả kỹ thuật trong khoảng từ trên $90 \%$ có mức năng suất bình quân là gần 1,34 tấn/công $\left(1.000 \mathrm{~m}^{2}\right) /$ vụ và mức năng suất có thể đạt được trong điều kiện có thể tối ưu là 1,46 tấn/công $\left(1.000 \mathrm{~m}^{2}\right) / v u ̣$, do đó mức năng suất thất thoát do kém hiệu quả gây ra là 0,13 tấn/công $\left(1.000 \mathrm{~m}^{2}\right) /$. Tương tự cho các nhóm mức hiệu quả khác được thể hiện trong Bảng 6. Với mức năng suất bình quân chung của các nông hộ trên điạ bàn nghiên cứu đạt được là 1,10 tấn/công $\left(1.000 \mathrm{~m}^{2}\right) / v u ̣$ và mức năng suất bình quân mà mỗi nông hộ có thể đạt được khi tối ưu là gần 1,27 tấn/công $\left(1.000 \mathrm{~m}^{2}\right) /$. Cho thấy, mức năng suất bình quân bị thất thoát do kém hiệu quả kinh tế tạo ra là gần 0,19 tấn/công $\left(1.000 \mathrm{~m}^{2}\right) / v u ̣$. Năng suất thất thoát này có thể được xem là khoảng mất mát đáng kể, bởi nó chiếm đến gần $17,27 \%$ mức năng suất bình quân thực tế mà các nông hộ đang đạt được. Cho nên nếu có giải pháp cải thiện hiệu quả, sẽ góp phần làm gia tăng đáng kể năng suất cho nông hộ.

\section{Kết luận và kiến nghị}

Hoạt động sản xuất bắp lai ở ĐBSCL, có năng suất trung bình đạt gần 1,10 tấn/công $(1.000 \mathrm{~m} 2) / v u ̣$. Chi phí sản xuất bình quân (chưa bao gồm chi phí lao động gia đình) là 2,28 triệu đồng/công/vụ cho nên có mức giá thành sản xuất bình quân là 2,07 ngàn đồng/kg. Với mức giá sản phẩm bán ra bình quân tại thời điểm khảo sát là 3,96 ngàn đồng/kg nên lợi nhuận bình quân đạt gần 1,89 đồng/kg và 2,06 triệu đồng/công/vụ. Tuy nhiên mức lợi nhuận đạt được 
có sự chênh lệch khá lớn giữa các nông hộ, và giữa các địa phương trong vùng, đặc biệt có khoảng 4,2\% nông hộ bị thua lỗ.

Mức hiệu quả kỹ thuật mà các nông hộ đạt được cũng có sự biến động (từ 48,73 $97,44 \%$ ) và có sự chênh lệch giữa các địa phương trong vùng. Mức hiệu quả kỹ thuật bình quân đạt được của các nông hộ trên địa bàn nghiên cứu là 84,63\%, với mức hiệu quả này, trung bình khoảng năng suất thất thoát do kém hiệu quả kỹ thuật (chưa đạt hiệu quả tối ưu) tạo ra là gần 0,19 tấn/công/vụ. Việc kém hiệu quả kỹ thuật trong sản xuất được tạo ra bởi các nguyên nhân chủ quan và khách quan nhưng trong đó có phần rất lớn $(58 \%)$ từ nhóm các nguyên nhân chủ quan (nguyên nhân nông hộ có thể kiểm soát).

Để nâng cao hiệu quả kỹ thuât, dựa trên kết quả phân tích, nghiên cứu đề xuất một số giải pháp sau:

Tập trung đẩy mạnh tuyên tuyền, hướng dẫn nhằm nâng cao nhận thức trong việc sử dụng các nguồn lực đầu vào, đặc biệt các vấn đề liên quan đến nâng cao trình độ kỹ trong sản xuất cho nông hộ như: nâng cao tỉ lệ sống sau gieo thông qua lựa chọn giống chất lượng, nâng cao kỹ thuật chuẩn bị đất và gieo hạt; tăng số vụ gieo ở mức hợp lý và tránh sản xuất bắp lai liên tục nhiều năm trên một mãnh đất; phát huy lợi thế kinh nghiệm trong sản xuất thông qua hoạt động chia sẻ kinh nghiệm lẫn nhau giữa các nông hộ, tiến tới xây dựng phát triển các mô hình kinh tế hợp tác trong sản xuất bắp lai. Mặc dù theo kết quả ước lượng yếu tố tập huấn không ảnh hưởng đến hiệu quả kỹ thuật nhưng các hoạt động vừa nêu ở trên chủ yếu thực hiện thông qua công tác tập huấn. Chính vì thế, cần cải thiện nâng cao chất lượng và nội dung của hoạt động tập huấn để nội dung tập huấn thật sự thiết thực hơn cho hoạt động sản xuất, thu hút được sự quan tâm của nông hộ.

Bên cạnh đó, nhà nước cần phải quy hoạch và phân vùng tập trung sản xuất để có chiến lược đầu tư và tổ chức sản xuất có trọng điểm và hiệu quả hơn, bởi thực chất không phải địa phương nào trong vùng cũng đều có lợi thế so sánh và đạt được hiệu quả cao trong sản xuất. Song song đó, cần tiếp tục đầu tư và hoàn thiện cơ sở hạ tầng điện, thủy lợi phục vụ sản xuất và nâng cao ứng dụng cơ giới hóa.

\section{Tài liệu tham khảo}

Aigner, D., Lovell, C. A. K., \& Schmidt, P. (1977). Formulation and estimation of stochastic frontier production function models. Journal of Econometrics, 6(1), 21-37.

Ali, F., Parikh, A., \& Shah, M. (1994). Measurement of profit efficiency using behavioural and stochastic frontier approaches. Applied Economics, 26(2), 181-188.

Battese, G. E., \& Coelli, T. J. (1992). Frontier production functions, technical efficiency and panel data: With application to paddy farmers in India. Journal of Productivity Analysis, 3(1/2), 153-169.

Farrell, M. J. (1957). The measurement of productive efficiency. Journal of the Royal Statistical Society, 120, 253-290. 
Jondrow, J., Lovell, C. A. K., Materov, I. S., \& Schmidt, P. (1982). On the estimation of technical inefficiency in the stochastic frontier production function model. Journal of Econometrics, 19(2/3), 233-238.

Maddala, G. S. (1997). Econometrics. Kogakusha, Japan: McGraw - Hill.

Meeusen, W., \& van Den Broeck, J. (1977). Efficiency estimation from Cobb-Douglas production functions with composed error. International Economic Review, 18, 435-444.

Nguyen, H. D. (2012). Hiệu quả kỹ thuật và các yếu tố ảnh hưởng đến hiệu quả kỹ thuật của nông hộ trồng lúa ở ĐBSCL, Việt Nam trong giai đoạn 2008 -2011 [Technical efficiency and factors affecting technical efficiency of rice farmers in the Mekong Delta, Vietnam in the period 2008 - 2011]. Ký yếu Khoa học Trương Đại học Cần Tho', 267-276.

Pham, L.T., Huynh, T. D. X., \& Tran, T. T. D. (2011). So sánh hiệu quả kinh tế của vụ lúa Hè Thu và Thu Đông ở ĐBSCL [Comparing the economic efficiency of Summer-Autumn and Autumn-Winter rice crops in the Mekong Delta]. Tạp chí Khoa hoc Truờng Đại hoc Cần Tho, 18(a), 267-276. 